\title{
A IMPORTÂNCIA DA INSERÇÃO DA CULTURA DA PAZ NO CURRÍCULO ESCOLAR
}

\author{
Michelle Popenga Geraim Monteiro ${ }^{1}$ \\ Tatiane Delurdes de Lima-Berton ${ }^{2}$ \\ Araci Asinelli-Luz ${ }^{3}$
}

\begin{abstract}
RESUMO
O objetivo do presente estudo é salientar a importância da inserção da Cultura da Paz no currículo escolar para a prevenção das violências na infância no ambiente escolar, visto que a escola tem sido considerada um espaço de expressão e manifestação da violência. É resultado de uma análise qualitativa e tem como metodologia o estudo bibliográfico, decorrentes de pesquisas de abordagem teórica, relacionadas ao Mestrado em Educação da Universidade Federal do Paraná. No contexto social e educacional, em defesa de uma escola com base humanizadora, amplia-se o olhar para o âmbito do desenvolvimento do currículo escolar, aliado à Cultura da Paz como forma de compreensão e prevenção do fenômeno das violências. Acredita-se que ao compreender a escola como espaço de interações, cujos valores são pautados no diálogo e no respeito, aumenta-se a chance concreta de uma realidade educativa melhor e de prevenção das violências.
\end{abstract}

Palavras-chave: Cultura da Paz. Educação. Infância. Prevenção.

\section{THE IMPORTANCE OF INSERTING THE PEACE CULTURE IN THE SCHOOL CURRICULUM}

\section{ABSTRACT}

The aim of this study is to highlight the importance of inserting the Culture of Peace in the school curriculum for the prevention of violence in childhood in the school environment, since the school has been considered as a space for expression and manifestation of violence. It is the result of a qualitative study and its methodology is the bibliographic study, resulting from research with a theoretical approach, related to the Master in Education at the Federal University of Paraná. In the social and educational context, in defense of a school with a humanizing base, the scope of the school curriculum development is broadened, together with the Culture of Peace as a way of understanding and preventing the phenomenon of violence. It is believed that by understanding the school as a space for interactions, whose values are guided by dialogue and respect, the concrete chance of a better educational reality and violence prevention is increased.

Keywords: Culture of Peace. Education. Childhood. Prevention.

Recebido em: 9/3/2020

Aceito em: 6/4/2020

\footnotetext{
1 Autora correspondente. Universidade Federal do Paraná. Cutritiba/PR- Brasil. http://lattes.cnpq.br/5283794394494090. https://orcid. org/0000-0003-3058-8987. mizinhadobru@yahoo.com.br

2 Universidade Federal do Paraná. Curitiba/PR, Brasil. http://lattes.cnpq.br/0418895883177728. https://orcid.org/0000-0001-6653-2593.

3 Universidade Federal do Paraná. Curitiba/PR, Brasil. http://lattes.cnpq.br/9511955646520341. https://orcid.org/0000-001-5880-0543.
} 
A infância, caracterizada pela primeira fase de desenvolvimento do homem, é apresentada como o período de construção humana de necessidade de cuidados, zelo e atenção para o crescimento saudável. É o momento na qual o sujeito se descobre, sendo uma demanda de afeto, aprendizagens e constituição de limites para que se possibilite a construção da cidadania. As crianças são caracterizadas como seres ativos, autônomos e culturais, que contribuem para a formação humana e comunitária, assim como os demais atuantes da sociedade. Com as influências diretas e indiretas que sofrem, devido às interações sociais e às ausências delas, faz-se necessário que se assegure a esses sujeitos a promoção de direitos humanos fundamentais (LOPES; PASCHOALICK, 2014).

Da infância, tem-se a segunda fase do desenvolvimento humano, caracterizada pela adolescência, a qual corresponde à idade cronológica de 10 a 19 anos, segundo a Organização Mundial da Saúde (OMS, 2014). É compreendida pelas transformações corporais, fisiológicas e sociais, de construção biológica e estruturação da personalidade. Trata-se de um momento importante para a formação do sujeito, visto que promove a relação entre o desenvolvimento psicológico, social, emocional e cognitivo com os aspectos cerebrais, sexuais e da puberdade. São elementos que formarão o adulto, de continuidade da construção do potencial mental, físico e social.

"Ser protagonista" segundo Azevedo, Fernandez e Pescarolo (2012), significa incluir os indivíduos como aqueles que constroem histórias por intermédio dos adultos e por influência de fatores internos e externos. Com isso, precisa-se estimular o protagonismo das crianças e dos adolescentes, orientá-los em aspectos de desenvolvimento e interação social para que assim seja garantida a melhoria da qualidade de vida. Em consonância com a Constituição Federal de 1988, em seu Artigo 227:

É dever da família, da sociedade e do Estado assegurar à criança e ao adolescente, com absoluta prioridade, o direito à vida, a saúde, à alimentação, à educação, ao lazer, à profissionalização, à cultura, à dignidade, ao respeito, à liberdade e à convivência familiar e comunitária, além de colocá-los a salvo de toda forma de negligência, discriminação, exploração, violência, crueldade e opressão.

A partir da Constituição Federal de 1988, a criança deixou de ser reconhecida como "carente" e passou a ser vista como cidadã de direitos. Em 1990, o Estatuto da Criança e do Adolescente (ECA) situa a criança como prioridade, relacionada às questões de proteção e prevenção à violação de seus direitos. Para tal a educação, em seu contexto de construção individual e coletiva, precisa viabilizar ações que reforcem a proteção das crianças e adolescentes e assim possibilite a garantia de seus direitos tanto por meio do apoio de métodos de comunicação (imprensa, redes sociais) quanto pelo fortalecimento de políticas públicas e/ou monitoramento da família e comunidade, havendo nessa perspectiva uma rede de proteção efetiva, eficiente e eficaz.

A vida em sociedade exige uma relação entre sujeitos e estas relações são complexas e, em determinados momentos, conflituosas. Entende-se que a violência tem percorrido um longo caminho dentro da História da humanidade. Ela tornou-se um problema global e urgente. A generalização do fenômeno faz com que a sociedade, de modo geral, esteja suscetível à sua participação e consequências. Considerando estes desdobramentos, pode-se observar que o conceito de violência é amplo e atinge o ser humano de diversas formas. Muitas são as violências, que implicam diferentes atores e 
sendo vivenciadas de formas diferentes. Por isso, conceituar violência vai muito além de apenas definir como uma forma de agressividade contra o outro, mas mostra "a multidimensionalidade e a complexidade deste conceito. Se o objeto é complexo, fica claro que não daremos conta dele de forma simplista" (SCHILLING, 2008, p. 3).

Para garantir que as interações sociais fossem adequadas a princípios de convivência, ao longo da História, os direitos humanos foram construídos e identificados devido às manifestações de inúmeras formas de violência presentes no meio social. $A$ constituição de uma sociedade harmoniosa, entretanto, não depende apenas desses princípios, mas de sujeitos sensíveis que compreendam seu papel como cidadãos, construindo e lutando pela paz. Um dos desafios vividos no cotidiano escolar nos últimos tempos é o aumento significativo das violências. Refletindo sobre isso, a escola atualmente enfrenta uma demanda social vulnerável que está associada ao enfraquecimento da escola, contrapondo-se à promoção de uma melhor qualidade de vida para os estudantes (MONTEIRO, 2017).

Nesse sentido, o contexto social oscila entre os princípios da paz e da transgressão e, ao longo da História, muitas estratégias foram criadas e desenvolvidas para a preservação da paz, com a intenção de garanti-la a todos. A paz caracteriza-se como um conceito amplo que "contempla relações sociais caracterizadas pela ausência da violência e pela presença de justiça, igualdade, respeito e demais elementos que primam pela dignidade humana" (DUSI, 2006, p. 1). Assim sendo, verifica-se que as questões referentes à prevenção, na perspectiva da Cultura da Paz, precisam ser consideradas acerca dos direitos humanos e, por isso, a escola, como instituição formadora, tem em sua essencialidade a função de instruir para a convivência em sociedade.

Posto isto, o currículo pode ser conceituado de diferentes formas e receber diversas significações de acordo com os contextos culturais e seu processo educativo. A palavra currículo em suas raízes etimológicas sugere a tradução para percurso/caminho e, portanto, é entendida no ambiente escolar como uma forma de organização do ensino escolar para a condução dos estudantes de determinada localidade, na concretização das próprias funções da escola. O interesse pelo estudo dessa área surgiu no início do século 20, quando as transformações econômicas, tecnológicas e do trabalho exigiram da educação uma formação mais direcionada e específica no que diz respeito ao desenvolvimento social e econômico da sociedade. Assim, houve diversos movimentos educacionais que mostraram formas diferentes de se enxergar a escola (SANTIAGO; NARVAES; BORGMANN, 2012).

Entende-se assim que a organização escolar deve valorizar as relações coletivas estabelecidas de modo a facilitar a construção do conhecimento, considerando a amplitude da complexidade do comportamento e desenvolvimento humano em prol da paz. Daí a importância da introdução de valores sociais e conceitos da Cultura da Paz que priorizem o respeito e a dignidade humana, prevenindo as violências que estão arraigadas no ambiente escolar. $\mathrm{O}$ ambiente da escola precisa ser construído de forma pacífica, no cotidiano, por meio de pequenas ações, gerando autoconhecimento, tolerância e afeto. A paz precisa ser atitude (UNESCO, 2010; NUSSBAUM, 2015). 
Há a preocupação em ressignificar o contexto vivenciado pelas crianças e adolescentes, em uma perspectiva de formação humana integral, de garantia de direitos humanos. É necessário ampliar estudos e práticas na área de prevenção das violações de direitos e das violências, dando maior visibilidade à temática. Essas ações possibilitam a formação de agentes multiplicadores, de educadores capazes de auxiliar na proteção da infância e adolescência, assim como a família. Deve-se reforçar discussões, a fim de despertar o protagonismo juvenil, a relevância da convivência em sociedade e a corresponsabilidade de todos serem agentes transformadores de suas realidades.

Sendo assim, as considerações relacionadas às vivências de violência presenciadas por crianças conduzem o presente artigo para a seguinte questão norteadora: Por que é importante inserir a Cultura da Paz no currículo escolar para a prevenção das violências na infância? Pensa-se na perspectiva Cultura da Paz de modo a construir diálogo e transformação social por meio da educação - essa, humana e humanizadora, seguindo os princípios do respeito e tolerância social.

E para o presente artigo assume-se a dimensão humanizadora de prevenção, indicando-a como processo de conhecimento, crescimento e desenvolvimento do ser humano como um todo. Trata-se de um estudo qualitativo, teórico e bibliográfico. Evidencia-se neste estudo a infância, as suas condições biopsicossociais, em universos históricos, políticos, econômicos e sociais. Pensa-se na perspectiva da Cultura da Paz e sua importância no currículo escolar, com o objetivo geral de salientar a importância da sua inserção no currículo escolar para a prevenção das violências na infância. Desse modo, tem-se como objetivo evidenciar a Cultura da Paz na prevenção de violências na infância e adolescência e sua importância no currículo escolar. A partir de agora aborda-se a violência na infância e suas extensões na escola.

\section{A VIOLÊNCIA NA INFÂNCIA E SUAS EXTENSÕES NA ESCOLA}

O cenário da sociedade atual denuncia a complexidade que é vivenciar a infância e a adolescência devido a situações de extrema vulnerabilidade e risco social, bem como dificuldades enfrentadas por suas famílias, envolvendo violência física, moral, sexual, psicológica e de outras naturezas. O bullying, negligência familiar, abuso de drogas, tráfico, exploração sexual, são alguns dos fatores que influenciam e refletem diretamente no desenvolvimento dos sujeitos. As consequências que a violência gera são muitas e afetam todos os envolvidos, direta ou indiretamente, e, por isso, é considerada um fenômeno sistêmico, porque suas proporções evidenciam atitudes tanto individuais quanto coletivas, seguido de um contexto que favorece sua amplitude e disseminação.

Há a preocupação em proporcionar um ambiente saudável, com oportunidade da aquisição de conhecimentos, de mudança em seus espaços, de superação de problemáticas, de transformações de suas vidas no futuro, reforçando a importância da inclusão social e melhoria da qualidade de vida. É necessário pensar na construção do ser sadio para a expansão de suas possibilidades, visto que as violências não são apenas questão de injustiça social, de opressão, mas principalmente de ausência de perspectiva de futuro: "A desumanização, que não se verifica apenas nos que têm sua humanidade roubada, mas também, ainda que de forma diferente, nos que a roubam, é distorção da vocação do ser mais" (FREIRE, 1987, p. 16). 
Discussões sobre vulnerabilidade e risco social na infância e adolescência mostram-se importantes devido ao impacto causado no comportamento, bem como as mudanças envolvendo as relações, o histórico dos sujeitos, seus processos e o próprio ambiente em que estão inseridos (BRONFENBRENNER, 2011). A falta de compreensão e suporte às demandas básicas de desenvolvimento das crianças e adolescentes por parte de seus responsáveis, sejam eles pais ou educadores, culminam também em violação de direitos, como estabelecido no ECA (BRASIL, 1990).

Muitas situações de violação de direitos ocorrem nos espaços que deveriam ser os fundamentais para a preservação da infância e adolescência, por exemplo, a família e a escola. Assim, consideram-se a família e a escola espaços que estruturam e proporcionam a socialização e se revelam essenciais para o desenvolvimento humano e, por isso, a importância de estarem em harmonia e equilíbrio. A instituição escolar, por sua função social, de convivência, necessita atentar-se às situações de vulnerabilidade e risco social, uma vez que o desempenho acadêmico dependerá também dos ambientes e das relações que nela se estabelecerão, visto que é neste ambiente que ocorrerão muitos momentos de convívio entre pares, experiências coletivas e formação de identidade. Por outro lado, ainda vivenciam-se muitas situações de violência dentro da escola e são cada vez mais frequentes, tanto em suas formas quanto nos atores envolvidos. Nesse contexto de conflitos na escola, reconhece-se que é ainda mais complexo conceituar a violência, uma vez que ela é reconhecida como um problema social (SCHILLING, 2008). Alguns documentos e avaliações de aprendizagem internacionais mostram que a violência, como o bullying escolar, reduz as expectativas de conquistas dos estudantes em relação ao seu futuro acadêmico. Em seu estudo mais recente, a Unesco (2019) mostra que $44 \%$ das crianças que sofrem violência na escola não esperam terminar o Ensino Médio e $65 \%$ desenvolvem ansiedade.

Charlot (2002) distingue, em um de seus estudos, a violência escolar em três modalidades: violência na escola, à escola e da escola. A violência na escola é aquela que ocorre dentro do espaço escolar, pois ali se encontram indivíduos passíveis e sujeitos de ações violentas. A violência à escola é aquela direcionada para a escola em si, como a destruição de patrimônio ou até mesmo a violência contra seus agentes. $E$ a violência da escola caracteriza-se por meio do tratamento da instituição em relação aos seus agentes e estudantes.

Nesse sentido, pode-se afirmar que a escola é um local de produção/reprodução e que em certos momentos oportuniza a violência em seu ambiente, seja por meio de atitudes, omissão ou fragilidade em sua função. Por isso, há urgência na inserção de mecanismos de prevenção que atuem nessas três vertentes e na produção de relações sociais saudáveis e harmoniosas, como cooperação, respeito e empatia, pois estas funcionam como suporte para o desenvolvimento humano.

A escola justa - que faz justiça social - é aquela que, sem degenerar, inclui, não exclui e qualifica as novas gerações. É aquela que lida com as heterogeneidades, as respeita e leva a aprendizagens eficazes. Ou seja, aquela escola em que os alunos aprendem de forma significativa e se educam para a vida como cidadãos. Assim, esse novo paradigma solicita cada vez mais que o profissional professor esteja pre- 
parado para exercer uma prática educativa contextualizada, atenta às especificidades do momento, à cultura local e ao alunado diverso em sua trajetória de vida e expectativas escolares (GATTI, 2013, p. 53).

A escola, na sua função social, precisa reforçar os espaços de aprendizagem baseados em relações sadias, convivência comunitária e o de interações horizontais. Além do processo de ensino-aprendizagem baseado no currículo, faz-se necessário estimular o diálogo, a mediação de conflito: observar como está o nível de motivação pessoal, disposição física. Envolvendo-se no processo de mediação de conflitos, faz-se necessário conhecer dimensões humanas e sociais. Como exemplo, a Cultura de Paz, que se aprende e se constrói pelos seres humanos, e a paz, que por sua vez não é uma disciplina, mas envolve todas as dimensões: políticas, culturais, éticas... e é para todos, em que o diálogo e a não violência tornam-se essenciais para esse processo. "Nenhum sistema educacional funciona bem se seus benefícios só alcançam as elites abastadas" (NUSSBAUM, 2015, p. 12). Por isso, justifica-se a inclusão de uma educação para a paz, que promove ações pedagógicas que incentivam a construção de valores sociais e o desenvolvimento humano saudável.

Educar para a paz é um processo de crescimento e valorização do ser humano e a compreensão deste conceito remete o educador a buscar um entendimento mais profundo da natureza humana, das relações interpessoais que existem nas ações preventivas e nos vínculos que vão sendo tecidos com a rede social da prevenção (ASINELLI-LUZ, 2003, p. 162).

Assim, a mediação de conflito constitui-se na construção de um espaço de consciência de si próprio e de ampliar a visão para os pontos de vista e as necessidades dos outros, obtendo melhores resultados na mediação dos problemas, na metodologia do círculo, resolução dos conflitos, a reintegração, o diálogo, a criação do senso comunitário, a compreensão, o apoio e o restabelecimento da convivência. Com a interação entre educador e educando há a expansão do diálogo sobre a Cultura da Paz nas famílias e na própria comunidade, possibilitando a prevenção da violência. Tornando-se ações de caráter informativas, sensibilizantes e de reflexão, é fundamental que todos os envolvidos no processo educativo consigam que todos os seus desejos, opiniões, ideias, sugestões, sejam expressos e discutidos no coletivo, ocorrendo envolvimento flexível, coerente e claro na organização das práticas (discentes, docentes, familiares e/ou comunitárias) para que permitam alterações e flexibilidade no processo de escolhas em suas vivências (ASINELLI-LUZ, 2003).

Para que a intervenção seja efetiva e adequada deve-se considerar e compreender o processo de formação da violência, em suas raízes culturais e históricas e, a partir disso, construir formas de lidar com ela e com os sujeitos envolvidos, que garantam o respeito às diferenças dentro do ambiente escolar. Nesse sentido, acredita-se que uma das formas que colaboram para essa mudança é a Cultura da Paz, pois ela é uma proposta, que pode até mesmo ser considerada uma metodologia de prevenção às violências e que permite que valores sociais invadam a escola e se insiram no cotidiano escolar, proporcionando ações de mudança colaborativas e harmoniosas. Para isso, entende-se que essas nuances de propostas educativas, tanto sobre o conhecimento das violências, 
bem como sobre a Cultura da Paz, devem ser inseridas no dia a dia da escola, fazendo parte integrante do currículo escolar. A seguir, apresenta-se a Cultura da Paz, seus conceitos e possibilidades de inserção no currículo escolar.

\section{CULTURA DA PAZ: Conceitos e Possibilidades no Currículo Escolar}

Discussões sobre a importância da formação humana sempre estiveram presentes no âmbito social e acadêmico. Formar pessoas para a cidadania ou para o mercado de trabalho? Hoje há uma crise do ensino humanista, parecendo este prejudicial para o futuro do desenvolvimento da democracia e das novas gerações. A corrida para o mercado de trabalho está diminuindo a capacidade de pensar criticamente como cidadãos do mundo. No cenário mundial, valores estão sendo esquecidos e diminuídos em detrimento do lucro. "Os países - e seus sistemas de ensino - estão descartando, de forma imprudente, competências indispensáveis para manter viva a democracia" (NUSSBAUM, 2015, p. 4). Esquece-se da igualdade, da paz, da qualidade das relações e do desenvolvimento humano. Por isso, há certa preocupação e urgência no retorno das humanidades, por meio da educação, com o objetivo principal de formar cidadãos conscientes e não apenas sujeitos passivos para o mercado. Cidadãos capazes de serem autônomos, tanto no âmbito individual quanto no social (NUSSBAUM, 2015).

A partir das reflexões sobre a importância da volta dos valores sociais, a Cultura da Paz é uma expressão que ganhou notoriedade nos dias atuais, em especial na área educacional. Ele refere-se à construção de valores e atitudes que previnem as situações de conflito e violência por meio do diálogo entre sujeitos. Assim, este conceito amplo sugere que a paz precisa ser ensinada e construída ao longo do processo de desenvolvimento do ser humano. "Como Cultura de Paz entende-se o grande campo de atividades humanas que levem em conta um mundo melhor, mais humano, mais feliz e sustentável. Assim, a Cultura de Paz cabe e vale para todos os seres humanos" (SALLES FILHO, 2016, p. 140).

Para que estes valores sejam solidificados e apreendidos pelo ser humano é necessária a projeção de ações concretas, primeiramente em âmbito individual, no sentido de melhoria do comportamento e da capacidade de se relacionar com o mundo, bem como em plano macro, por meio da mudança de processos sociais e públicos, como a melhoria de políticas efetivas e programas educativos que valorizem a paz. Essas mudanças, no entanto, exigem que as violências não conduzam mais às atitudes sociais e relacionais humanas (SALLES FILHO, 2016).

Precisamos de leituras críticas sobre os valores humanos e os valores de convivência, além de uma visão crítica sobre os direitos humanos. Junto a isso, precisamos igualmente, entender os processos de conflito entre pessoas, grupos e na sociedade, além de seus processos de mediação. Precisamos estender também o olhar sobre o meio ambiente, como nossa casa maior, onde as dimensões objetivas e subjetivas de nossa vida precisam ser valorizadas, no encontro entre mundo do trabalho, mundo da vida e a transcendência, constituindo o que chamamos de ecoformação (p. 141). 
Por isso, a construção da paz está na adesão a novas atitudes, na valorização dos princípios de construção do coletivo, nas novas formas de se relacionar com os pares, baseadas na empatia e tolerância, no entendimento da diversidade como necessária no mundo atual, no diálogo e cooperação como pontos positivos para uma vida em sociedade mais harmoniosa. Nesse sentido, na busca pela introdução de valores sociais que dignifiquem o ser humano no ambiente escolar, sugere-se a Educação para a Paz, vertente da Cultura da Paz que prioriza ações pedagógicas dentro das escolas que visam a ações de prevenção e mudanças cotidianas em prol da paz (SALLES FILHO, 2016).

A Educação para a Paz se constrói por meio de princípios e valores sociais e humanos, que priorizam a convivência saudável e harmoniosa. Cultivando valores na infância é ir na direção oposta à sociedade fria e individualista que se vive hoje, formando cidadãos que se importam com o outro, que são éticos, que não se calarão diante de preconceitos e injustiças e que poderão resolver conflitos de forma pacífica e positiva, acrescentando crescimento pessoal e social ao seu desenvolvimento (PAULA; SALLES FILHO, 2014).

Nesse processo, cabe ao ser humano admitir sua parcela de responsabilidade, assumindo sua participação social e valorizando os princípios da Cultura da Paz. "A paz é um processo constante, cotidiano, mas não passivo. A humanidade deve esforçar-se para promovê-la e administrá-la" (UNESCO, 2010, p. 15), pois viver em paz é o que todo ser humano deseja. A educação é uma alavanca para a promoção da paz nas escolas, pois é por meio dela que se aperfeiçoa a cidadania e a convivência entre pares.

Ao considerar as crianças que frequentam as escolas e o processo dinâmico de interação entre elas e com o próprio ambiente, as intervenções que ocorrem neste local favorecem ou não o desenvolvimento humano. Por isso, um ambiente harmonioso e equilibrado e um local que ofereça cuidado e proteção são formas de prevenção das violências nas escolas. Dessa forma, evidencia-se a Cultura da Paz integrada ao currículo escolar, de modo que essa abordagem possa fazer parte do cotidiano funcional das escolas. Trata-se de não apenas destacar a Cultura da Paz e os Direitos Humanos como conceitos em disciplinas específicas, mas sim de traspassarem e serem pertinentes a todas elas. Conforme a Base Nacional Comum Curricular (BNCC), o currículo escolar como o norteador para as instituições de ensino, destaca a abordagem transdisciplinar em virtude de ela contribuir com a construção de saberes que extrapolam o conteúdo escolar. Há maior flexibilização e articulação nas diferentes áreas de conhecimento. Assim sendo, pensa-se que "essa abordagem contribui para reduzir a fragmentação do conhecimento ao mesmo tempo em que busca compreender os múltiplos e complexos elementos da realidade que afetam a vida em sociedade" (BRASIL, 2019).

A educação para a paz não é uma solução para o que se chama violência e prevenção de guerras, mas um modo de problematizar determinados acontecimentos e remetê-los a um conjunto de práticas sociais, econômicas, políticas, culturais, históricas, educativas, comunitárias, familiares e de jogos diplomáticos internacionais (LEMOS; GALINDO, 2012, p. 135).

Sendo assim, as escolas de modo geral, devem atentar para a qualidade das relações entre os estudantes, para que dentro de um ambiente assertivo e construtivo possam desenvolver formas seguras e sadias de lidar com os conflitos, uma vez que 
havendo uma sensibilidade moral adequada, as crianças desenvolvam sentimentos de empatia, diminuindo assim práticas violentas nas escolas. Nesse processo de mudança na qualidade das relações e na cultura escolar, é importante valorizar o ensino na área de Humanas nas escolas, pois são essas que conduzem ao crescimento pessoal e ao pensamento crítico no sujeito. Elas precisam ser destacadas no processo de construção do currículo, se o desejo for a formação de cidadãos conscientes e autônomos (NUSSBAUM, 2015).

Toda sociedade traz em si pessoas que estão preparadas para conviver com os outros em termos de respeito mútuo e de reciprocidade e pessoas que buscam o conforto da dominação. Precisamos compreender como produzir mais cidadãos do primeiro tipo e menos do segundo (NUSSBAUM, 2015, p. 29).

A escola, sendo um local de gestão, compartilhamento de saberes, relações e interações sociais, faz com que o currículo seja o centro dos estudos. Nessa perspectiva, não se pode deixar de refletir sobre os contextos e os sujeitos que dela participam. Ela defende a formação crítica, a convivência social, cidadã e democrática. Quando se reflete sobre o aprendizado da criança há diversos fatores que surgem como importantes e necessários, não somente o lado cognitivo, mas o emocional e o social, que estão presentes em todo o ser humano. Pensando assim, acredita-se na importância de adaptações no dia a dia escolar, atitudes que levem os estudantes, professores e comunidade escolar a pensarem sobre suas relações e vivências, pois "não se pode estruturar uma pedagogia das convivências à margem dos que são diretamente afetados por ela". (JARES, 2008, p. 19). Há, sim, a necessidade do desenvolvimento da sensibilidade, da afetividade e da ternura no espaço escolar.

O contexto escolar, dessa forma, enquanto espaço de manifestação e vivência da realidade subjetiva do sujeito, a despeito do reconhecimento e da relevância social dos demais campos nos quais se insere, apresenta-se como lócus privilegiado de observação e intervenção frente à realidade social. Espaço de formação e aprendizagem, a instituição educativa envolve uma ação para além do espaço cognitivo ou da prática curricular, constituindo um espaço de interações sociais, crescimento integral e construção cultural (DUSI, 2006, p. 29).

Defende-se a educação voltada para a construção do sujeito reconhecendo suas experiências e identidades, analisando seu sentido político-cultural, tornando um espaço pedagógico em que são levantadas questões relevantes sobre os elementos que organizam a base da subjetividade e da experiência do aluno. Isso ocorre por que a cultura popular situa-se no cotidiano e é organizada em torno das experiências vividas pelo aluno, enquanto a educação é definida por uma estrutura organizacional e sistemática, tendo a aprendizagem e as relações sociais envolvidas junto à comunidade, família, aluno, professores e gestores de escola (MOREIRA; SILVA, 2000).

Mesmo com o ideal de currículo, no contexto escolar ainda reafirma-se a existência de deficiências teóricas e práticas que desafiam as bases para a efetivação docente, observadas em algumas escolas (falta ou precariedade de materiais didáticos, propostas curriculares com valorização conteudista, não utilização de tecnologias, impasses em enfrentar a realidade social, fragmentação de disciplinas). Para a efetividade escolar 
há a necessidade de compreender as demandas advindas dos sujeitos, das dificuldades e problemáticas que assombram o desenvolvimento da criança (MORIN, 2003; ROMERO, 2009).

A contribuição da escola à redução das desigualdades sociais não se efetivará sem o enfrentamento crítico e corajoso dos inúmeros impedimentos que se colocam à construção da cidadania e que comparecem tanto no interior dos muros da escola (pelo currículo formal, real, oculto), quanto fora dela, por meio de políticas públicas que atestam o descaso com necessidades, desejos e demandas concretas oriundas no contexto escolar (ARAÚJO, 2003, p. 23).

O currículo, seja oculto, real ou formal, exerce influência nas relações entre funcionários da escola e alunos, pois é o conjunto de valores e normas que marcam as relações escolares, sendo implícito e explícito nos planos de ensino, considerando expressar os ideais dos grupos sociais. Assim, a função do currículo é oferecer valores, conhecimentos que deverão defender uma visão no processo ensino e aprendizagem, de consciência dos atos, permitindo então mudanças.

Dusi (2006, p. 55) reforça que a instituição escolar precisa exercer no currículo a competência ética (baseada na educação e valores), na técnica (para exercício de funções na sociedade) e política, devido à cidadania e a convivência em sociedade:

Educar para a paz inclui, nessa perspectiva, um imperativo legal para a abordagem dos temas transversais no currículo, considerando-se as razões pedagógicas, sociais, políticas e ecológicas que sustentam e demandam a prática educativa.

Refletindo sobre essa noção de competência no ensino, ela pode ser vista como criadora de justiça social, de igualdade, baseada em saberes do ensino geral, de desenvolvimento humano e construção de cidadania. Essas competências podem ser compreendidas como uma tentativa de substituir uma hierarquização de conhecimentos e práticas, dando importância às diferenças e particularidades individuais. Com tudo isso, a teorização recente do currículo e sua consequente problematização devem subsidiar uma relação mais profunda acerca da educação brasileira, em que uma escola se faz de um fator de comprometimento das desigualdades sociais.

A superação das desigualdades sociais, da promoção da cidadania e da erradicação da discriminação está descrita no Plano Nacional de Educação (PNE), em que objetiva todas as esferas do processo educacional - desde a formação básica do sujeito até a valorização dos profissionais de ensino.

Art. 2o São diretrizes do Plano Nacional de Educação:

I - erradicação do analfabetismo;

II - universalização do atendimento escolar;

III - superação das desigualdades educacionais, com ênfase na promoção da cidadania e na erradicação de todas as formas de discriminação;

IV - melhoria da qualidade da educação;

$V$ - formação para o trabalho e para a cidadania, com ênfase nos valores morais e éticos em que se fundamenta a sociedade;

VI - promoção do princípio da gestão democrática da educação pública;

VII - promoção humanística, científica, cultural e tecnológica do país; 
VIII - estabelecimento de meta de aplicação de recursos públicos em educação como proporção do Produto Interno Bruto - PIB, que assegure atendimento às necessidades de expansão, com padrão de qualidade e equidade;

IX - valorização dos(as) profissionais da educação;

$X$ - promoção dos princípios do respeito aos direitos humanos, à diversidade e à sustentabilidade socioambiental (BRASIL, 2010).

Assim, buscam-se por meio de documentos normativos, como o PNE, processos educativos vinculados à epistemologia da prática, em que a educação dialogue sobre a problematização do contexto do aluno, transpondo relações entre as experiências que se promovem no dia a dia (reflexão e ação). As teorias pedagógicas possuirão validade quando vinculadas à prática concreta do sujeito e sua comunidade, trabalhando na construção coletiva dos conhecimentos, promoção das ideias e resoluções às situações em que emergem exercício da criticidade, da dialogicidade e do potencial transformador. Assim como destacado por Morin (2003), pensar complexamente resultará em um conjunto de novas reflexões, visões e descobertas.

A partir das interações, serão construídos repertórios de experiências, conhecimentos práticos, em que o docente perpassará o seu conhecimento, tornando sua prática como um ensinamento da leitura crítica a seus alunos, em um processo de inacabamento e mobilização constante. Essa busca pelos novos processos educativos estará vinculada à epistemologia da prática, em que a educação será voltada para a problematização do contexto do sujeito, transpondo maiores intercâmbios em sala de aula (a experiência que se promove no dia a dia, a reflexão antes, durante e após a ação). Nesse contexto, Pimenta (2010, p. 2) ressalta que "frente a novas situações que extrapolam a rotina, os profissionais criam, constroem novas soluções, novos caminhos, o que se dá por um processo de reflexão na ação".

Trabalhando as estratégias (probabilidades e improbabilidades) o docente expandirá seus conhecimentos relacionados ao campo educacional, em que, se tratando de um ambiente criativo, de diversidade, necessitará de ferramentas para trabalhar com os possíveis riscos e soluções de problemas. Para isso é necessário respeitar tanto o aluno quanto o professor, as suas histórias de vida, contextos, necessidades e expectativas, possibilitando um processo educativo de reciprocidade e crescimento coletivo.

Diante disso, a relação professor-aluno (enfoque político-filosófico na sala de aula), necessitará manter a reciprocidade no processo de conhecimento, constituindo-se de uma educação com relação horizontal entre o sujeito e o meio, na busca pela humanização e cuidado do outro. Isso se aproxima com o enfoque filosófico que Aquino (1996) estabelece ao dialogar sobre a interação dentro da sala de aula, em que o professor e o aluno se encontram para o processo de troca de conhecimento/interação eficaz.

Acreditamos que à medida que o agente educativo se reconheça enquanto "Sujeito Complexo", poderá assumir seu papel como docente/discente no cotidiano educacional, ou seja, se assumir enquanto coprodutor da realidade, inquisidor, criativo, colaborador (labor em conjunto); buscando sistematicamente o global, o multidimensional e o complexo nos saberes tratados nas instituições de ensino, e assim se preparando mais efetivamente para uma existência mais relevante e feliz, tanto individual como coletivamente (SANTOS, 1995, p. 6). 
Nesse contexto, Gatti (2013) reforça que para efetivar as propostas de um ensino contextualizado, completo e justo, a prática docente necessitará atender às demandas do momento, da cultura local, integrando a trajetória de vida com as expectativas dos sujeitos. Para isso, pode-se integrar as matrizes curriculares à apropriação dos espaços disponíveis na comunidade, como as Unidades Básicas de Saúde, espaços culturais e esportivos, equipamentos de Assistência Social (Centros de Referência da Assistência Social, Centros da Juventude, projetos sociais), parques, praças e outros espaços, efetivando interações entre sujeito, contexto, processo e tempo.

Para efetivar a prática educativa sustentada em perspectivas de construção coletiva baseadas na totalidade do sujeito, os profissionais se ancorarão em áreas de especialidades, de formação continuada para que possibilitem uma sensibilidade cognitiva capaz de ampliar a visão de mundo dos educandos. É essencial a construção de espaços de relacionamentos didáticos frutíferos, abrindo possibilidades para a valorização cultural dos indivíduos (GATTI, 2013).

Ressalta-se a necessidade da criação de programas de prevenção efetivos que priorizem uma Cultura de Paz nas escolas e possíveis mecanismos de intervenção contra ações violentas, uma vez que as consequências são para todos os envolvidos na comunidade escolar, considerando, assim, as violências como um fenômeno sistêmico que atinge proporções elevadas. Por isso a importância de formação adequada para os professores, atividades bem planejadas e aulas bem preparadas, pois a Educação para a Paz ocorre nas atitudes diárias, no viver o respeito e a tolerância. Nesse sentido, ao pensar em projetos que tentem minimizar ou "sanar" esse processo nas escolas é necessário que se envolva toda a comunidade escolar, justamente porque o processo de minimização do fenômeno envolve as pessoas e os ambientes. Logo, é necessário ter um olhar sobre os fatores que levam os estudantes a terem atitudes violentas, identificando assim problemas interpessoais, partindo do pressuposto da análise destas relações e dos seus ambientes, como sistemas interdependentes (MONTEIRO, 2017).

\section{CONSIDERAÇÕES FINAIS}

Tendo em vista as abordagens realizadas neste estudo, que salientou a importância da inserção da Cultura da Paz no currículo escolar, pensa-se que a Educação para a Paz é um processo educativo que visa à promoção de valores e conceitos éticos por meio de ações pedagógicas direcionadas e específicas que possibilitam a construção da Cultura da Paz. Os valores como respeito e empatia são fundamentais para a formação de sujeitos generosos e solidários. Este processo de valorização de princípios que favorecem a paz nas escolas, a Educação para a Paz, é uma das formas de prevenção das violências e entende-se a importância de estes estarem atrelados ao conjunto de ações da escola: o currículo, uma vez que a ampliação da temática, agregando aos valores da escola e de suas funções, apoia o estabelecimento de mecanismos que promovem estas questões no ambiente escolar. Sendo assim, as escolas de modo geral devem atentar para a qualidade das relações entre os estudantes, para que dentro de um ambiente assertivo e construtivo possam desenvolver formas saudáveis de lidar com os conflitos. 
Isso posto, não é possível negar as relações que se estabelecem entre as violências e os princípios da Cultura da Paz, uma vez que a sociedade entende a violência como processo de construção social e naturaliza ações violentas como normais. Há uma tendência social em justificar ações agressivas e violentas como brincadeiras infantis, postergando a identificação do fenômeno no ambiente escolar. Nesse sentido, a escola e a sociedade atuam na identificação das raízes culturais, revendo seus conceitos e valores e estabelecendo novas formas de desenvolver seu currículo, inserindo os valores sociais e humanos no seu dia a dia. Partindo deste princípio, para se construir a Cultura de Paz e desenvolver a Educação para a Paz é necessário discutir alguns pressupostos da violência, a fim de se compreender o real sentido do conflito. Pensar em questões sociais como pobreza, injustiças e direitos humanos, vistas como formas de violência estrutural, que atingem a sociedade e, consequentemente, a escola, compreendidas como forma de dominação do mais forte ao mais fraco, são necessárias, ao passo que a construção de uma base sólida da paz na sociedade vem a partir do entendimento da forma como a violência é manifestada.

É preciso que a escola trabalhe com a sensibilização e com a conscientização de um ambiente acolhedor e pacífico, para contribuir com uma qualidade das relações interpessoais na escola. A escola como um todo precisa refletir sobre as condutas e sobre a forma como as interações sociais estão ocorrendo em seu interior, para promover políticas de prevenção e intervenção efetivas, bem como nas atividades e atitudes diárias, que trabalhem e estimulem os estudantes a viverem de forma cooperativa.

A edificação de uma educação de qualidade é um conjunto construído pela família, comunidade, discentes, docentes e todos os responsáveis que influenciam direta ou indiretamente o ensino, uma conexão horizontal, de articulações sociais presentes nos espaços de atuação, possibilitando a aprendizagem e o incentivo das potencialidades dos sujeitos a partir de suas necessidades e interesses. Dentro do território, Santos (1995) destaca que se pode construir comunidades de aprendizagens, ampliando o currículo de maneira a fornecer sentido aos sujeitos, vivenciar a cidadania, promover a transformação social, potencializando a própria cultura e as tomadas de decisão. Além disso, Nussbaum (2015) salienta a importância da valorização das humanidades e no retorno dos valores sociais como potencializadores da formação da democracia e de cidadãos críticos e autônomos.

A construção da Cultura da Paz e da Educação para a Paz se faz por meio do diálogo e da compreensão de valores que se opõem à violência com a intenção de compreender o real sentido do conflito social e das condições que causam vulnerabilidades. Por isso, há a necessidade de construção de políticas públicas efetivas e eficazes que se adéquem à realidade brasileira, promovendo condições melhores para o desenvolvimento humano das crianças nas escolas. Na condição de educadores, de agentes multiplicadores em defesa da infância e da adolescência, deve-se buscar ações preventivas capazes de proporcionar o protagonismo, a emancipação, o altruísmo, condições de garantia, preservação dos direitos fundamentais e contribuir para o processo de transformação social e de desenvolvimento humano. É por meio do diálogo, da tolerância, da escuta ativa e de valores positivos que se pode fazer um mundo mais humanizado, no qual todos possam enxergar o outro e a si mesmos com valor e respeito. 


\section{NOTA}

O presente trabalho foi realizado com apoio da Coordenação de Aperfeiçoamento de Pessoal de Nível Superior - Brasil (Capes) - Código de Financiamento 001.

\section{REFERÊNCIAS}

ASINELLI-LUZ, Araci. Planejando a cultura de paz e a prevenção da violência na escola. In: MILANI, Feizi Masrour; JESUS, Rita de Cássia Pereira de (org.). Cultura da paz: estratégias, mapas e bússolas. Salvador: Inpaz, 2003.

AQUINO, Júlio Groppa. Confrontos na sala de aula: uma leitura institucional da relação professor-aluno. São Paulo: Summus Editorial, 1996.

ARAÚJO, Claysi Marinho. Psicologia escolar e desenvolvimento de competências: uma opção para a capacitação continuada. 2003. Tese (Doutorado) - Universidade de Brasília, 2003.

AZEVEDO, Mariana Corrêa de; FERNANDEZ, Soledad; PESCAROLO, Joyce Kelly. Plá, por um lugar adolescente: material para educadores. Curitiba: Parabolé, 2012.

BRASIL. Lei Federal no 8.069, de 13 de julho de 1990. Institui o Estatuto da Criança e do Adolescente e dá outras providências. Diário Oficial da União, Brasília, Distrito Federal, 1990/2013.

BRASIL. Ministério da Educação. Projeto de Lei: Estabelece o Plano Nacional de Educação - PNE para o decênio 2011-2020, e dá outras providências. Brasília, 2010.

BRASIL. Ministério da Educação. Temas contemporâneos transversais na BNCC: contexto histórico e pressupostos pedagógicos. Brasília, 2019.

BRONFENBRENNER, Urie. Bioecologia do desenvolvimento humano: tornando os seres humanos mais humanos. Porto Alegre: Artmed, 2011.

CHARLOT, Bernard. A violência na escola: como os sociólogos franceses abordam essa questão. Sociologias. Porto Alegre, v. 4, n. 8, p. 432-443, 2002.

DUSI, Miriam Lúcia Herrera Massotti. A construção da cultura da paz no contexto da instituição escolar. 2006. 196 f. Dissertação (Mestrado em Psicologia) - Universidade de Brasília, 2006.

FREIRE, Paulo. Pedagogia do oprimido. 23. ed. Rio de Janeiro: Paz e Terra, 1987.

GATTI, Bernadete A. Educação, escola e formação de professores: políticas e impasses. Educar em Revista, Curitiba, n. 50, p. 51-67, out./dez. 2013.

HAGIBZANG, L. F.; KOLLER, S. H. Violência contra crianças e adolescentes. Porto Alegre: Artmed, 2012.

JARES, Xésus. Pedagogia da convivência. Trad. Elisabete de Moraes Santana. São Paulo: Palas Athena, 2008

LEMOS, Flávia Cristina Silveira; GALINDO, Dolores Cristina Gomes. Violência escolar - em xeque a proposta da cultura da paz no Ensino Médio. Dialogia, São Paulo, n. 16, p. 129-140, 2012.

LOPES, Jandicleide Evangelista; PASCHOALICK, Rosele Ciccone. Direitos Humanos e Direitos Fundamentais de crianças e adolescentes: concepções de infância e adolescência na sociedade brasileira. Curitiba: Secretaria do Estado da Criança e da Juventude, 2014.

MATOS, Margarida; NEGREIROS, Jorge; SIMÕES, Celeste; GASPAR, Tânia. Violência, bullying e delinquência: gestão de problemas de saúde em meio escolar. Lisboa: Coisas de Ler, 2009.

MONTEIRO, Michelle Popenga Geraim. O bullying segundo a percepção dos estudantes do 5o ano do Ensino Fundamental. 2017. 148 f. Dissertação (Mestrado em Educação) - Setor de Educação, Universidade Federal do Paraná, Curitiba, 2017.

MOREIRA, Antonio Flávio; SILVA, Tomaz Tadeu da. Currículo, cultura e sociedade. 4. ed. São Paulo: Cortez, 2000.

MORIN, Edgar. A cabeça bem-feita: repensar a reforma, reformar o pensamento. Tradução Eloá Jacobina. 8. ed. Rio de Janeiro: Bertrand Brasil, 2003.

NUSSBAUM, Martha. Sem fins lucrativos: porque a democracia precisa das humanidades. São Paulo: Editora WMF: Martins Fontes, 2015.

OMS. Organización Mundial de la Salud. Salud para los adolescentes del mundo: una segunda oportunidad en la segunda década. Genebra, Suíça: Organización Mundial de La Salud, 2014.

PAULA, Silvani Silva de; SALLES FILHO, Nei Alberto. Educação para a paz: por uma pedagogia da convivência no cotidiano escolar. In: GOVERNO DO ESTADO DO PARANÁ. Os desafios da escola pública paranaense na perspectiva do professor PDE, 2014. Cadernos PDE, versão on-line. ISBN 978-85-8015-079-7 
PIMENTA, Selma Garrido. Professor reflexivo: construindo uma crítica. In: PIMENTA, Selma. Garrido; GHEDIN, Elodie (org.). Professor reflexivo no Brasil: gênese e crítica de um conceito. São Paulo: Cortez, 2010. ROMERO, Emilio. Para uma psicopatologia da vida cotidiana: tendências sociais dissolventes e conflitantes: os desafios e ameaças na vida cotidiana. In: RIBEIRO, Wânier; ROMERO, Emilio (org.). Vulnerabilidade humana e conflitos sociais: por uma psicologia social compreensiva. São José dos Campos: Della Bídia, 2009. p. 107-142. Cap. 5.

SALLES FILHO, Nei Alberto. Pedagogia dos direitos humanos no contexto da educação para a paz: elementos a partir dos estudos de Johan Galtung. In: CONGRESSO DE DIREITOS HUMANOS E POLÍTICAS PÚBLICAS, 2016. Curitiba. Anais [...]. Curitiba, 2016.

SANTIAGO, Anna Rosa Fontella; NARVAES, Andréa Becker; BORGMANN, Marta Estela. Cultura, escola e currículo. Ijuí. Editora Unijuí, 2012.

SANTOS, Milton. As humanidades, o Brasil, hoje: dez pontos para um debate. In: JANCSÓ, István. Humanidades, pesquisa, universidade. São Paulo: FFLCH-USP, 1995. V. 1., n. 1.

SCHILLING, Flávia. Educação em direitos humanos: reflexões sobre o poder, a violência e a autoridade na escola. Universitas Psychologica, 2008. p. 685-695. V. 7.

UNESCO. Organização das Nações Unidas para a Educação, a Ciência e a Cultura. Cultura de paz: da reflexão à ação; balanço da Década Internacional da Promoção da Cultura de Paz e Não Violência em Benefício das Crianças do Mundo. Brasília: Unesco. São Paulo: Associação Palas Athena, 2010. 256 p.

UNESCO. Organização das Nações Unidas para a Educação, a Ciência e a Cultura. Behind the numbers: ending school violence and bullying. France: Unesco, 2019. 